\title{
THE ROLE OF HIGHER EDUCATION INSTITUTIONS IN RESKILLING THE WORKFORCE
}

\author{
Karen Paullet, Robert Morris University, USA, paullet@rmu.edu \\ Diana Behling, Sentara Healthcare, Inc., USA, djbehling@msn.com \\ Robert Behling, Arrow consulting, USA, behlingr@hotmail.com
}

\begin{abstract}
In today's economy, the skills and technologies needed to gain a competitive edge are constantly changing. Improving worker productivity is essential in any organization and the reskilling of the existing workforce becomes a necessity. The primary goal of this paper is to highlight and discuss the role of higher education institutions in reskilling the workforce and provide recommendations for systematic reskilling or upskilling the workforce.
\end{abstract}

Keywords: Upskilling, reskilling, workforce, higher education institutions

\section{INTRODUCTION}

Our technology-driven world is filled with promise as the global economy enters a phase of dynamic reorganization. Millions of new jobs are being created, but qualified workers are in short supply to fit many of the newly created positions (Delotte \& Aspen Institute, 2018) McKinsey and Company estimates that as much as one-third of the U.S. workforce will need to learn new skills and work in new occupations by 2030 (Manyika et al., 2017). Skill development and employability are key challenges for the workforce both globally and in the United States with most industries impacted by worker skills gaps. Sixty-four percent of human resource leaders responding to a 2019 survey reported significant skills gaps in the available workforce (Gallo, 2019), and the top trend for 2019 is the need to improve learning and development opportunities to meet evolving skills requirements (Global Human Capital Trends, 2019).

The driving force to control costs and maintain and grow profits for all service and manufacturing industries begins with improving worker productivity. When we look at any job function in today's economy, the skills and technologies needed to succeed are constantly changing. According to a recent report by McKinsey and Company, as much as one-third of the U.S. workforce may need to learn new skills and find work in new occupations by 2030 (Manyika et al., 2017), and the ability to learn new skills will be critical for workers wishing to stay workforce relevant (Knowledge@Wharton, 2018). For example, jobs in the health care industry are expected to increase much faster than those in the general economy (Gallo, 2019) and reskilling has the potential to help meet workforce requirements and provide improved job security, leading to a more productive and stable work environment (Moon, 2018). In addition, O'Brian (2019) reported that 5 of the 7 in-demand jobs in 2019 were in the areas of healthcare. These were medical services manager. annual median salary, registered nurse, medical technologist, nursing assistant, and home health aide.

For the clinical nurse leader, for example, the emphasis has shifted from providing necessary and appropriate patient medical support to the implementation and utilization of technology and the management of data to coordinate and laterally integrate patient care within, across care settings and among healthcare providers. Clinical nurse leaders are now expected to be able to analyze current and proposed patient care technologies, including determining costeffectiveness and appropriateness. They are also tasked with ongoing evaluation and integration of various emerging technologies, as well as utilizing technology to disseminate patient healthcare information and communicate effectively. Clinical nurse leaders can no longer rely on their clinical expertise to successfully lead in today's modern health care setting. A very different skill set, driven by the deployment and utilization of various technologies, databases, and communication systems to manage healthcare today mandates our educational system develop and deliver programs to provide upskilling training and provide these very critical clinical nurse leaders with the tools to effectively meet today's health care challenges. 
Due to advancements in artificial intelligence (AI) the healthcare industry is being revolutionized. AI is being used to prevent dosage errors, provide medicine, automatic treatments or manage non-patient activities such as detecting fraud. According to Gartner (2017), AI will create more jobs than it eliminates. These gains will especially be seen in the health care sectors. Gartner (2017) also predicts that AI and other emerging technologies will generate \$2.9 trillion in business and recover 6.2 billion hours of workers' productivity.

In the tech domain alone, White (2020) reported that the ten most in-demand tech jobs for 2020 are AI architect, business intelligence analyst, cloud architect, data analyst/scientist/engineer, developer web/software/mobile, DevOps engineers, help desk and desktop support professionals, network/cloud administrator, network security/architect/engineer/ administrator, and systems administrator. The demand for these skills at 75th and 95th percentile requires strong skills, certifications, and specializations among others (White, 2020).

Productivity can often be increased by substituting technology and automation for human work activities (Manyika et al., 2017). With the increase in the use of Artificial Intelligence, automation and other technologies, the half-life of human skills has fallen to about five years (Resourcing Edge, 2019). It is estimated that as much as 50\% of current work activities can be automated utilizing existing technologies (Manyika et al., 2017). The pace of implementing automation will be determined by the cost of developing and deploying technology-driven solutions, the quality and quantity of the available labor force, labor wage scales, and regulatory and social acceptance. In the healthcare workforce, automation is expected to have less impact on jobs involving applying expertise and social interaction (Manyika et al., 2017).

In America, the need for skilled workers has outpaced the supply, and many leaders see developing and reskilling their existing workforce as an effective way to remain competitive (Delotte \& Aspen Institute, 2018). Reskilling is training individuals who have shown they have the aptitude to learn a completely new occupation, learning new skills and competencies to transition to a different career or job, addressing the changing workforce requirements (Resourcing Edge, 2019).

In health care, jobs are expected to increase much faster than the general economy, and analysis by the Bureau of Labor Statistics comparing employer demand and labor supply, demand in health care exceeds supply by $44 \%$ (Gallo, 2019). Training and development of existing employees may be one of the most effective ways to meet the emerging skills challenges (Delotte \& Aspen Institute, 2018).

In the white-collar workforce such as hospital administration, the rise of specialized and technical skills requires almost constant upskilling and reskilling to keep pace with innovation. Organizations have been slow to address these human issues and commit adequate resources to allow the workforce to keep pace with the constant changes they encounter. The U.S. employers' budget for training and development is constantly declining and organizations are beginning to recognize this deficiency and are moving forward to provide employees critical development opportunities. The ability to learn new skills will be critical for individuals to stay competitive in the job market, and many organizations are now beginning to pay more attention to supporting employee reskilling (Knowledge@Wharton, 2018). Educational requirements for occupations expected to grow are generally higher than those for jobs displaced by automation (Manyika et al., 2017).

According to Bate (2018), cybersecurity jobs are heterogeneous. Cybersecurity and technology jobs cover essentially every industry to include the corporate and private sectors, non-profits, academia, government and health care sectors among others. In a study conducted by the Linux Academy in 2019, there are $17 \%$ more job openings in technologyrelated jobs than there are available workers in the market. Additionally, $70 \%$ of executives say that current employees lack the appropriate technology and computer skills and only $11 \%$ of executives feel that college graduates will be prepared for the workforce after graduation. It is estimated by 2020 that 5 million positions could go unfilled costing the economy $\$ 160$ billion a year (Irena, 2019). Advancements in technology will not fix the workforce gap but will change the requirements needed for technology-based jobs. This change will require the reskilling of the current workforce to become proficient with technology abilities (Bate, 2019).

Looking at cybersecurity as an interdisciplinary field across law, policies, healthcare, academia, government, and private sectors can help close the skill gap noting that there are jobs in all industries specific to technology that can benefit by reskilling the workforce. According to Bate (2018), "lasting solutions will require a network of connected 
policies and community-wide efforts." As of 2018, it is estimated that the shortfall of cyber and technology workers is close to 3 million. Bate (2019) recommends that we need to create alternative educational opportunities and entry points into the field. This also will yield great diversity in the workforce.

The traditional 4-year bachelor's degree in a computer-related field is not always the answer. In order to successfully retrain the workforce, there must be more options. According to a 2014 National Science Foundation Report, cybersecurity is a "multidisciplinary problem, touching on policy issues, economic incentives, and public and business awareness and education, along with new technical challenges." Training programs need to incorporate elements from numerous fields and backgrounds. Part of the issue surrounding the field of cybersecurity is that technology changes so quickly. This makes conventional training very hard to keep up with. "The existence of a diverse array of alternatives to conventional education could enable learners to successfully transition into cybersecurity jobs (Bate, 2018).”

ISC2 (2019) conducted a Cybersecurity Workforce Study which collected data from 3, 237 individuals in June and July of 2019 of workers responsible for security/cybersecurity work throughout North America, Europe, Latin America, and Asia-Pacific. Of those who responded, $22 \%$ were from IT services, $8 \%$ financial services, $6 \%$ manufacturing, $6 \%$ healthcare, $5 \%$ education, $5 \%$ engineering and $5 \%$ retail encompassed the top industry distribution. The cybersecurity workforce gap increased to 500,000 from the previous year in 2018. In order to fill the new gap in the United States, the cybersecurity workforce needs to grow by $62 \%$ to meet the needs of the business. The global gap is estimated at 4.07 million which means that the global workforce needs to grow by $145 \%$ to meet the demands of the field (ISC2, 2019). The ISC2 study also revealed that there are key items that hinder people from entering the field to include the cost of certifications, people are unclear of the opportunities in the field, and the cost of formal education is among the results.

The G20 Young Entrepreneurs Alliance (2019) produced a report on how to accelerate skills in the age of intelligent technologies. Their findings revealed three key areas. The first is to speed up experiential learning. Skills are taught through hands-on application. The second is to shift focus from institutions to individuals. This is where companies can broaden skills within each worker. They can cross-train workers on a variety of skills within the organization. The third is to empower vulnerable learners. Workers who are vulnerable to changes in technology advancements must be identified so that new skills can be taught. This particular type of worker needs the most attention but is noted for participating less in training opportunities. Incentives need to be put in place to retrain the workforce.

\section{THE ROLE OF UNIVERSITIES IN UPSKILLING AND RESKILLING THE WORKFORCE}

Individuals working in the financial markets to the medical profession and every opportunity in between have seen an increased need for digital skills in their line of practice. For instance, AT\&T is investing \$1 billion in web-based training with leading universities so that their employees can gain new skills that will keep up with the need for the changes to technology. AT\&T states that nearly half of its 250,000 lack the technical skills needed to keep the company competitive. Approximately, $90 \%$ of companies expect digital disruption but only $44 \%$ are adequately preparing to re-train their employees (Caminiti, 2018). Corporations partnering with academic institutions are a prime example of how companies are helping to close the skills shortage.

In order to achieve and maintain high levels of productivity and profitability, organizations have begun investing significant resources in retraining and reskilling their workers rather than attempting to recruit qualified new hires. It has been shown that regular learning and development programs are cost-effective when compared to hiring new employees, and organizations retaining key employees by reskilling from within will have a competitive advantage Deloitte \& Aspen Institute, 2018). Institutional partnerships with universities, colleges, technical schools, and community colleges offer the opportunity to provide a wide range of learning opportunities (Manyika et al., 2017). From badges, credentials, certifications, to college degrees, higher education is teaming up with the industry to address upskilling and or reskilling challenges. For example, Fall (2017) reported on various models of upskilling the workforce, i.e., apprenticeship, employee training, certifications, and college degrees among others. At Amazon, employees can take advantage of the Amazon Career Choice program that pays 95 percent of the tuition to complete certificates and two-year programs at partner higher education institutions (Fall, 2017). APLU (2018) stated that 
higher education institutions in partnership with industries are innovating to provide learning opportunities to re-skill the workforce.

In 2016, six universities launched the University Learning Store ( See https://universitylearningstore.org/), to offer innovative industry-validated micro-credentials for working professionals for the purpose of upskilling or re-skilling the workforce. These universities include Georgia Tech Professional Education, UCLA, University of California, Davis Extension, University of California Irvine Division of Continuing Education, University of Washington Professional and Continuing Education and the University of Wisconsin-Extension. The micro-credentials include a domain of power skills, technical skills, and business skills.

\section{CONCLUSIONS}

Delivering upskilling educational programs presents many challenges. Some of the more important ones are: 1) screening and selection of candidates for the program; 2) establishing guidelines, standards and quality control measures for a diverse student population; 3 ) integrating a diverse student population to maintain a measurable and appropriate educational outcome; 4) addressing current technological and other workforce needs; and 5) developing and maintaining faculty skills to deliver relevant programs

Selecting candidates. There are numerous challenges, perhaps the most difficult to overcome is the need for an organization to train certain individuals they already have employed in dead end jobs, yet they may not meet the minimum program requirements. Unlike traditional university programs, where students are selected from a population competing for acceptance into a program, upskilling often has a built-in population which may or may not integrate well into the relevant educational framework. There is no easy solution for the student population problem, and it will continue to be a challenge to both university administrators and teaching faculty.

Establishing guidelines. Traditional programs have a long history to rely on to establish learning and performance guidelines. Industry often has active rather than static guidelines, so from year to year they often change significantly. Also, most faculty are not active in industry, therefore may not be very familiar with developing and meeting the needed guidelines. Without a clear history and tradition, upskilling programs are much harder to define and deliver. Integrating a diverse population. The industrial and service workforce has a very diverse and wide-ranging skill set, knowledge base, work ethic and expectations. Individuals may or may not cooperate with instructors and other students, may not be capable of doing and/or keeping up with assignments, and may have social issues. Putting a diverse population in the same room (physical or virtual), with the same goals and challenges, is a challenging task, but must be met.

Addressing technology and other current workforce needs. Upskilling education introduces an entirely new set of educational goals. For example, a program that accepts students with a Bachelor's in any discipline to form a cohort for a Master's in Nursing challenges curriculum design to meet the occupational needs while not overwhelming the students. With a goal of preparing students to pass the state Registered Nurse Examination, accelerated science courses may present a significant challenge to students with an English background or computer science/information technology background, along with many others. Identifying needed skill sets and technology familiarity will be a demanding task requiring forward thinking and visionary individuals.

Developing and maintaining faculty skills. Higher educational institutions expect faculty to do research as a part of their overall job description. While this will often lead to cutting edge thinking, it is usually focused on a single topic. Upskilling will require a broader base of understanding by faculty, along with constantly working to keep up with the times. This might mean being tuned in to current and future workforce requirements, current and future skill sets needed, and so forth. There may have to be incentives, supported training programs, collaboration with business and industry, and a myriad of other activities to make it work effectively.

Higher education institutions can play a significant role in reskilling or upskilling the workforce. They can make a direct contribution to the well-being and growth of technology-driven business enterprises and the training needs of employees. To do this, we recommend that higher education institutions look at reskilling or upskilling the workforce in a systematic way. We recommend the following: 
1. Determine the skills needed for the workforce, look at the most in-demand/high-demand careers.

2. Create the corporate-education partnership to address the upskilling of the workforce.

3. Agree upon program models for reskilling the workforce, i.e., digital badges, micro-credentialing, certificates, and/or degrees.

4. Design the programs having "learning" in mind. Learning should be active and based on the creation of knowledge. These programs should be designed for working professionals. The programs should be rightto-the-point and engaging. The design of the courses in the program should include exploration, scaffolding, higher-order thinking - analysis, evaluation, \& synthesis.

5. Recruit and assign appropriate faculty, providing adequate learning resources and support tools with monitoring ongoing learning activities.

6. Design appropriate student support services.

Progress, whether in business, services, or government, comes with a human resource as well as financial cost. Organizations are now beginning to recognize that this cost, as well as the accelerated pace of change, is putting pressure on their ability to meet their commitments and deliver quality products and services. This has become a global issue, and the foundation for dealing with rapid change is maintaining a skilled and educated workforce. Management can lead but cannot deliver satisfied customers or appropriate products and services without a skilled workforce. Higher education can play a significant role in helping organizations meet today's workforce skills requirements. Incorporating upskilling programs into their university curriculum offerings provide an opportunity for organizations and employees to stay relevant. It also opens a new market for university life-long learning programs. These cutting-edge programs can also provide a challenge for educators to stay on top of their discipline and deliver state-of-the-art knowledge.

\section{REFERENCES}

APLU (n.d.). Scaling success: higher education responding to 21st APLU century workforce needs. Retrieved January 30, 2020 from https://www.aplu.org/library/scaling-success-higher-education-responding-to-21stcentury-workforce-needs/file

Bate, L. (2018) Cybersecurity Workforce Development: A primer. New America, Florida International University. Retrieved January 30, 2020 from https://d1y8sb8igg2f8e.cloudfront.net/documents/Cybersecurity_Workforce_Development_A_Primer_201 8-10-31_175830_YMwa3ZJ.pdf

Caminiti, Susan (2018, March 13). AT\&T’s $\$ 1$ billion gambit: Retraining nearly half of its workforce for jobs of the future. CNBC. Retrieved January 30, 2020 from https://www.cnbc.com/2018/03/13/atts-1-billion-gambitretraining-nearly-half-its-workforce.html

Columbus, L. (2019). Data scientist is the best job in America according to Glassdoor's 2018 rankings. Retrieved January 30, 2020 from https://www.forbes.com/sites/louiscolumbus/2018/01/29/data-scientist-is-the-bestjob-in-america-according-glassdoors-2018-rankings/\#1bcd3a3d5535

Daxx (2019). software developer shortage in the US 2019. Retrieved January 30, 2020 from $\mathrm{https}$ ://www.daxx.com/blog/development-trends/software-engineer-shortage-us-2019

Deloitte \& Aspen Institute (2018). A Guide to Upskilling America's Frontline Workers. Retrieved January 30, 2020 from https://assets.aspeninstitute.org/content/uploads/2018/03/Upskilling_Employer_Handbook_042015.pdf

Fall, J. (2017). Models for Upskilling. Retrieved January 30, 2020 from https://www.aspeninstitute.org/publications/upskill-playbook-models-upskilling/

Gallo, S. (2019). Displaced by automation: Reskilling workers for health care careers. Retrieved January 30, 2020 from https://trainingindustry.com/articles/compliance/displaced-automation-reskilling-workers-for-healthcare-careers/

Gartner, (2017, December 13). Gartner says by 2020, artificial intelligence will create more jobs than it eliminates. Gartner Newsroom Press Release. Retrieved January 30, 2020 from https://www.gartner.com/en/newsroom/press-releases/2017-12-13-gartner-says-by-2020-artificialintelligence-will-create-more-jobs-than-it-eliminates 
Global Human Capital Trends (2019). Leading the Social Enterprise: Reinvent with the Human Focus. Retrieved January 30, 2020 from https://www2.deloitte.com/content/dam/insights/us/articles/5136_HC-Trends2019/DI_HC-Trends-2019.pdf

Irena (2019, April 2). Understanding the tech skills gap. Available from https://www.dailyinfographic.com/understanding-tech-skills-gap

ISC2 (2019). Strategies for building and growing strong cybersecurity teams. ISC2 Cybersecurity Workforce Study 2019. Retrieved January 30, 2020 from https://www.isc2.org/-/media/ISC2/Research/2019-CybersecurityWorkforce-Study/ISC2-Cybersecurity-Workforce-Study2019.ashx?la=en\&hash=D087F6468B4991E0BEFFC017BC1ADF59CD5A2EF7

Knowledge@Wharton (2018) The Future of Jobs in the New World of AI and Robotics. Retrieved January 30, 2020 from https://knowledge.wharton.upenn.edu/article/future-jobs-world-ai-robotics/

LinkedIn (2018). LinkedIn 2018 emerging jobs report. Retrieved January 30, 2020 from https://economicgraph.linkedin.com/en-us/research/linkedin-2018-emerging-jobs-report

Manyika, J. and S. Lund, M. Chui, J. Bughin, J. Woetzel, P. Batra, R. Ko, and S. Sanghvi. (2017). Jobs Lost, Jobs Gained: What the Future of Work Will Mean for Jobs, Skills, and Wages. Retrieved January 30, 2020 from www.mckinsey.com/featured-insights/future-of-work/jobs-lost-jobs-gained-what-the-future-of-work-willmean-for-jobs-skills-and-wages

Moon, K. (2018). Exit Line: The Effects of Employee Turnover on Manufacturing. Retrieved January 30, 2020 from https://Knowledge.wharton.upenn.edu/article/effects-of-employee-turnover-on-manufacturing/

NSF (2014, February 10). Interdisciplinary Pathways towards a more secure internet. National Science Foundation, Report on the Cybersecurity Ideas Lab, Arlington, VA.

O'Brian, S. (2019) Here are the most in-demand jobs for 2019. Retrieved January 30, 2020 from https://www.cnbc.com/2019/01/24/here-are-the-most-in-demand-jobs-for-2019.html

Resourcing Edge (2019). Upskilling and Reskilling In-House Employees to Solve Recruiting Problems. Retrieved January 30, 2020 from https://resourcingedge.com/recruiting/upskilling-reskilling-employees-solverecruiting-problems/

TAG (n.d.). Driven by innovation and proven by performance. Retrieved January 30, 2020 from https://www.tagonline.org/societies/fintech/

White, S. (2020). The 10 most in-demand tech jobs for 2020 - and how to hire for them. Retrieved January 30 , 2020 from https:/www.cio.com/article/3235944/hiring-the-most-in-demand-tech-jobs-for-2018.html 